GUIMARÃES, MA; LEMOS NETO, HS; ARAÚJO, RB; LIMA NETO, BP; SILVA, VB; MESQUITA, RO. 2017. Sistemas de tutoramento e espaçamentos de plantio na produção de feijão de metro. Horticultura Brasileira 35: 613-620. DOI - http://dx.doi.org/10.1590/S0102-053620170422

\title{
Sistemas de tutoramento e espaçamentos de plantio na produção de feijão de metro
}

\author{
Marcelo A Guimarães; Hozano S Lemos Neto; Romero B Araújo; Benedito P Lima Neto; Vinícius B Silva; \\ Rosilene O Mesquita
}

Universidade Federal do Ceará (UFC), Fortaleza-CE, Brasil; mguimara@ufc.br; hozanoneto@hotmail.com; romero.sako99@gmail.com; benepneto@hotmail.com; viniborrj@hotmail.com; rosilenemesquita@gmail.com

\begin{abstract}
RESUMO
A otimização de espaçamentos de plantio, bem como o uso de sistemas de tutoramento de plantas, são práticas culturais que têm melhorado a eficiência produtiva de várias espécies de hortaliças. Objetivou-se com este trabalho avaliar a produção do feijão de metro conduzido em diferentes sistemas de tutoramento e espaçamentos. $\mathrm{O}$ experimento foi conduzido no delineamento em blocos ao acaso, em esquema fatorial $(4 \times 3)$, com quatro repetições. O primeiro fator foi constituído por quatro formas de tutoramento [fitilho vertical (FV), "V" normal (VN), "V" invertido (VI) e rasteiro (R)]. O segundo fator foi constituído por três espaçamentos entre plantas $(20 ; 40$; e $60 \mathrm{~cm})$ mantendo-se fixo o espaçamento entre linhas de cultivo em $1 \mathrm{~m}$. Foram avaliados a precocidade de produção (ciclo de cultivo); número de vagens, massa de grãos e de vagens por planta; comprimento de vagens; número de grãos e massa de grãos por vagem; produtividade de grãos e de vagem. Também foram avaliadas as trocas gasosas, bem como o custo de implantação de cada um dos tratamentos. A densidade de 50.000 plantas/ha (espaçamento $20 \mathrm{~cm}$ ) foi a que proporcionou a maior produtividade nos sistemas FV e VI, com 9, 10 e $6,72 \mathrm{t} / \mathrm{ha}$, além de promover maior renda líquida ao produtor, com médias de aproximadamente 23 e 15 mil reais acima do sistema $\mathrm{R}$. Para as variáveis de trocas gasosas, houve redução na fotossíntese líquida com o incremento da densidade. Indica-se a utilização de maiores densidades de plantio combinadas com o uso dos sistemas de tutoramento FV e VI em detrimento ao sistema R, por gerarem maior produtividade e receita líquida ao produtor.
\end{abstract}

Palavras-chave: Vigna ungiculata var. sesquipedalis, rasteiro, trocas gasosas, custo de implantação, fitilho vertical.

\begin{abstract}
Staking system and planting spacing in the asparagus bean production

The optimization of plantation spacing, just like the use of staking plant systems, are cultural practices that have improved production efficiency of various kinds of vegetable. The aim of this study was to compare the asparagus bean cultivation conducted in different staking and spacing systems. The experiment was conducted in the design of randomized blocks in a factorial scheme $(4 \times 3)$ with four replicates. The first factor was constituted by four staking types [narrow ribbon vertical (FV), "V" normal (VN), inverted "V" (VI) and creeping (R)]. The second factor was constituted of three plant spacing $(20,40$, and $60 \mathrm{~cm}$ ), keeping constant the spacing of $1 \mathrm{~m}$ between crop rows. The evaluated characteristics were precocity (cultivation cycle); number of pods, mass of grains and pods per plant; length of pods; number of grains and mass of grains per pod; grain and pod yield. The gas exchange as well as the cost of deploying each of the treatments were also evaluated. The density of 50,000 plants/ha (spacing of $20 \mathrm{~cm}$ ) provided the highest productivity in the FV and VI systems, with 9.10 and $6.72 \mathrm{t} / \mathrm{ha}$, in addition to promoting higher net income to the producer, with averages of approximately 23 and 15 thousand $\mathrm{R} \$$ above $\mathrm{R}$ system. For the gas exchange variables, there was a reduction in net photosynthesis with density increase. The use of higher planting densities are indicated, combined with the use of FV and VI systems, in detriment to R system. The higher planting densities generate higher productivity and net income to the producer.
\end{abstract}

Keywords: Vigna ungiculata var. sesquipedalis, prostrated growth, gas exchange, deployment cost, vertical ribbon.

(Recebido para publicação em 15 de agosto de 2016; aceito em 25 de agosto de 2017)

(Received on August 15, 2016; accepted on August 25, 2017)

$\mathrm{O}$ feijão-caupi (Vigna unguiculata) também conhecido pelo nome de feijão-macassar ou feijão-de-corda, é uma planta de origem africana. Sua introdução no Brasil se deu por volta do século XVI (Freire Filho, 1981). Apesar de já amplamente disseminada e consumida no Brasil, essa espécie possui variedades ainda pouco exploradas comercialmente. Uma delas é a Vigna ungiculata var. sesquipedalis, conhecida popularmente como feijão de metro, considerada uma hortaliça-fruto (Sarutayopha et al., 2007).

No sudeste da Ásia é cultivada há muitas décadas, sendo consumida por uma grande parcela da população. No Brasil a sua produção ocorre principalmente em pequenas unidades de produção familiar localizadas na região
Norte e em algumas da região Nordeste. O cultivo do feijão de metro, nos locais citados acima, se da pelos motivos: tem importante papel na complementação da renda, diversificação de cultivos e segurança alimentar das populações; é rico em cálcio, fósforo e ácido ascórbico; tem sabor exótico, sendo utilizado na culinária tradicional em substituição ao feijão vagem (Feitosa et al., 2015); as 
vagens podem alcançar até $90 \mathrm{~cm}$ de comprimento (Kongjaimun et al., 2012); e apresenta excelente adaptação a climas quentes e úmidos (Piluek, 1994).

No Brasil, especificamente na região Norte, essa cultura é conduzida de forma tutorada, sendo raramente cultivada de forma rasteira. $\mathrm{O}$ cultivo rasteiro, apesar de apresentar a vantagem de não exigir investimento, no geral, proporciona baixa qualidade das vagens colhidas que, ao ficarem em contato com o solo úmido, apresentam suas epidermes manchadas na hora da colheita, o que causa rejeição do produto por parte do consumidor. Nesse sistema de produção há também a ocorrência do autosombreamento, com possibilidades reais de queda de produtividade já que pode ser reduzida a interceptação de luz pelas plantas e, consequentemente, a realização da fotossíntese. Além do exposto, a necessidade de maior espaço para o crescimento das plantas no cultivo rasteiro, acaba por promover uma menor densidade populacional de plantas por área, o que reduz sua eficiência produtiva (Marim et al., 2005).

Em geral, os problemas citados para o cultivo rasteiro não são verificados para o sistema tutorado. Neste sistema, por serem conduzidas de forma ereta ou inclinada, as plantas apresentam apenas parte de suas vagens, aquelas localizadas no terço inferior da planta, em contato com o solo e, consequentemente, com possibilidade de apresentarem baixa qualidade no momento da colheita. As demais, alocadas nos $2 / 3$ superiores da planta, tendem a apresentar a epiderme em perfeito estado no momento da colheita, tornando-se assim mais atrativas ao consumidor final. Também, o autosombreamento no sistema tutorado é reduzido e, consequentemente, a planta intercepta mais luz, o que possibilita a realização de maior taxa fotossintética. Além dos fatores já explanados, o sistema tutorado permite que as plantas possam ser cultivadas mais próximas umas das outras, já que menores áreas são ocupadas por estas, o que possibilita uma maior densidade. A principal desvantagem deste sistema é o investimento que deve ser feito na aquisição de infraestrutura e na instalação do sistema de tutoramento, geralmente elevado (Marim et al., 2005).

Apesar de haver no Brasil, regiões com características climáticas favoráveis ao cultivo do feijão de metro, pouquíssimos estudos têm sido realizados com o propósito de melhorar sua eficiência produtiva. De forma geral, sua produção ainda é bastante rústica, sendo cultivado de forma rasteira ou tutorado em estacas fincadas próximas às plantas. Baseado no exposto, esse trabalho teve como objetivo avaliar o rendimento produtivo e econômico do cultivo de feijão de metro em diferentes sistemas de tutoramento e espaçamento.

\section{MATERIAL E MÉTODOS}

O experimento foi realizado em campo em área pertencente à Horta Didática da Universidade Federal do Ceará, Campus Pici, em Fortaleza-CE ( $3^{\circ} 44^{\prime} \mathrm{S} ; 38^{\circ} 33^{\prime} \mathrm{O}$; altitude $19,5 \mathrm{~m}$ ), no período de agosto a outubro de 2014 . O clima do local segundo a classificação de Köppen, é do tipo Aw, tropical chuvoso. As médias de temperatura máximas e mínimas do período foram de 30,9 e $22,8^{\circ} \mathrm{C}$, sendo a precipitação acumulada de $16,75 \mathrm{~mm}$.

O trabalho foi conduzido no delineamento em blocos ao acaso, em esquema fatorial $(4 \times 3)$, com quatro repetições, sendo avaliadas seis plantas por parcela. $\mathrm{O}$ primeiro fator foi constituído por quatro formas de tutoramento [fitilho vertical simples (FV), "V" normal (VN), "V" invertido (VI) e a condução rasteira (R) das plantas]. O segundo fator constou de três espaçamentos entre plantas (20; 40 e 60 $\mathrm{cm}$ ), mantendo-se fixo o espaçamento entre linhas de cultivo em $1 \mathrm{~m}$.

Para o preparo do solo, foi realizada inicialmente a limpeza do terreno, de forma manual; em seguida, fez-se a amostragem do solo até a profundidade de $20 \mathrm{~cm}$, onde as amostras foram encaminhadas para análise físicoquímica sendo observadas as seguintes características: C.O. $=5,87 \mathrm{~g} / \mathrm{kg} ; \mathrm{P}=$ $27,08 \mathrm{mg} / \mathrm{kg} ; \mathrm{H}=1,70 \mathrm{cmol}_{\mathrm{c}} / \mathrm{kg} ; \mathrm{Na}=$ $0,23 \mathrm{cmol}_{\mathrm{c}} / \mathrm{kg} ; \mathrm{K}=80,00 \mathrm{cmol}_{\mathrm{c}} / \mathrm{kg} ; \mathrm{Ca}=$ $1,60 \mathrm{cmol}_{\mathrm{c}} / \mathrm{kg} ; \mathrm{Mg}=1,00 \mathrm{cmol}_{\mathrm{c}} / \mathrm{kg}$;
$\mathrm{Al}=0,10 \mathrm{cmol} / \mathrm{kg} ; \mathrm{SB}=62,64 \mathrm{cmol}_{\mathrm{c}} /$ $\mathrm{kg} ; \mathrm{CTC}=4,83 \mathrm{cmol} / \mathrm{kg} ; \mathrm{e}, \mathrm{V}=3,19$ $\mathrm{cmol}_{\mathrm{c}} / \mathrm{kg}$.

Com base na análise química de solo, procedeu-se a adubação de plantio e a correção da acidez com calcário calcítico. A adubação foi realizada, tomando-se como base as recomendações existentes para a cultura do feijão caupi indicados para o cultivo em solos cearenses (Aquino et al., 1993). Foram colocados $1,5 \mathrm{~kg}$ de composto orgânico (esterco bovino e restos culturais) por metro linear. Para a adubação de plantio utilizou-se ainda 6,4 $\mathrm{kg}$ de $\mathrm{P}_{2} \mathrm{O}_{5} ; 1,2 \mathrm{~kg}$ de $\mathrm{KCl}$ e $0,53 \mathrm{~kg}$ de N por metro linear. O restante do $\mathrm{N}(1,07$ $\mathrm{kg}$ ) foi aplicado em duas coberturas realizadas aos 20 e 40 dias após a semeadura. As fontes de nutrientes utilizadas foram superfosfato simples, cloreto de potássio e ureia.

A semeadura foi realizada de forma manual; utilizou-se três sementes por cova da cultivar "semente marrom", sendo realizado o desbaste aos sete dias após a semeadura (DAS), deixouse apenas uma planta por cova. Foram conduzidas as seguintes populações de plantas: espaçamento de $0,20 \times 1,0 \mathrm{~m}$ (50.000 plantas/ha), 0,40x1,0 m (25.000 plantas/ha) e 0,60x1,0 m (16.667 plantas/ ha). A irrigação foi manejada com base na evapotranspiração diária, sendo feita apenas a reposição diária da água, com base nos dados meteorológicos da estação experimental localizada no campus Pici. Usou-se fita gotejadora com vazão de $1,6 \mathrm{~L} / \mathrm{h}$. As plantas foram irrigadas duas vezes ao dia, início da manhã e fim da tarde, buscando-se sempre manter o solo entre 70 e $90 \%$ da capacidade de campo.

Para realização do tutoramento utilizou-se ripas de madeira fincadas ao solo, sendo estas dispostas a cada dois metros dentro das linhas de cultivo. As estacas tiveram seus ápices unidos por um fio de arame $\mathrm{n}^{\circ} 18$ a uma altura estimada de 2,20 m.

As vagens foram colhidas quando sua coloração começava a se alterar de verde escuro para verde claro e a apresentar aspecto inicial granado, ou seja, quando era possível identificar os pontos em que os feijões estavam dispostos antes de sua deiscência. Foram 
realizadas cinco colheitas, nas datas de 50, 55, 58, 63 e 70 DAS, ficando o período de colheita em torno de 20 dias.

Foram avaliadas as seguintes características: a) Precocidade de produção [(DAS) determinada através da contagem em dias, desde a semeadura até o início da colheita de cada um dos tratamentos]; b) Produção por planta $[(\mathrm{g} /$ planta $)$ realizou-se a pesagem individual das vagens de cada planta e fez-se a soma]; c) Número de vagens por planta (contagem somente do número de vagens comercializáveis de cada planta); d) Número total de vagens (soma do número de vagens comercializáveis de todas as plantas de cada tratamento); e) Comprimento médio de vagem $[(\mathrm{cm})$ realizado com o auxílio de uma régua graduada]; f) Número de grãos por vagem (contagem do número de grãos comercializáveis da vagem); g) Massa de grãos por planta [(g) realizada a pesagem dos grãos de todas as vagens da planta]; h) Massa de grãos por vagem $[(\mathrm{g})$ pesagem dos grãos da vagem]; i) Produtividade total de vagens $[(\mathrm{t} / \mathrm{ha})$ peso das vagens de todas as plantas e estimado para um hectare]; j) Produtividade total de grãos [(t/ha) peso dos grãos de todas as vagens e estimado para uma hectare]; j) Produtividade total [(t/ha) somatório da produtividade de grãos e vagens, ambos comercializáveis].

Um dia antes do início da colheita, entre as oito e dez horas, realizaramse as avaliações de trocas gasosas com o uso de um analisador de gás infravermelho (IRGA), modelo LCi da ADC. Foram avaliados: a) Concentração interna de $\mathrm{CO}_{2}\left(\mathrm{C}_{\mathrm{i}}, \mathrm{ppm}\right)$; b) Condutância estomática (gs, $\mu \mathrm{mol} /$ $\left.\left.\mathrm{m}^{2} / \mathrm{s}\right) ; \mathrm{c}\right)$ Fotossíntese líquida $(A, \mu \mathrm{mol} /$ $\left.\mathrm{m}^{2} / \mathrm{s}\right)$; d) Razão entre a concentração de $\mathrm{CO}_{2}$ na câmara subestomática e a concentração de $\mathrm{CO}_{2}$ do ambiente $(\mathrm{Ci} / \mathrm{Ca})$; e) Eficiência instantânea de carboxilação $\left(A / \mathrm{C}_{\mathrm{i}}\right)$, obtida pela razão entre a fotossíntese $(A)$ e $\mathrm{C}_{\mathrm{i}}$.

Os custos de implantação foram obtidos através da quantificação de todo material utilizado, além da mão de obra diária para implantação de cada um dos tratamentos. Com a quantificação de todo o material utilizado e as diárias necessárias para suas implantações, os custos de implantação foram calculados e então estipulados por ha.

Os dados coletados foram submetidos à análise de variância pelo teste $\mathrm{F}$. Para a comparação dos sistemas de tutoramento utilizou-se o teste de Scott-Knott, e para as variáveis quantitativas, empregou-se a análise de regressão. Utilizou-se para o procedimento das análises o software (Sisvar, v. 5.6) (Ferreira, 2011).

\section{RESULTADOS E DISCUSSÃO}

Com base nas análises de variância, observou-se que houve interação $(p \leq 0,01)$ entre os sistemas de tutoramento e espaçamentos para todas as características de produção avaliadas. Dessa forma, fez-se o desdobramento dos fatores e se estudou o comportamento de cada um deles para cada característica.

Para precocidade de produção, verificou-se um ajuste linear (Figura 1A), onde à medida que se reduziu o número de plantas (densidade), isto é, nos maiores espaçamentos $(0,6$ e 0,4 $\mathrm{m})$, foi maior a precocidade de produção para os sistemas de tutoramento fitilho

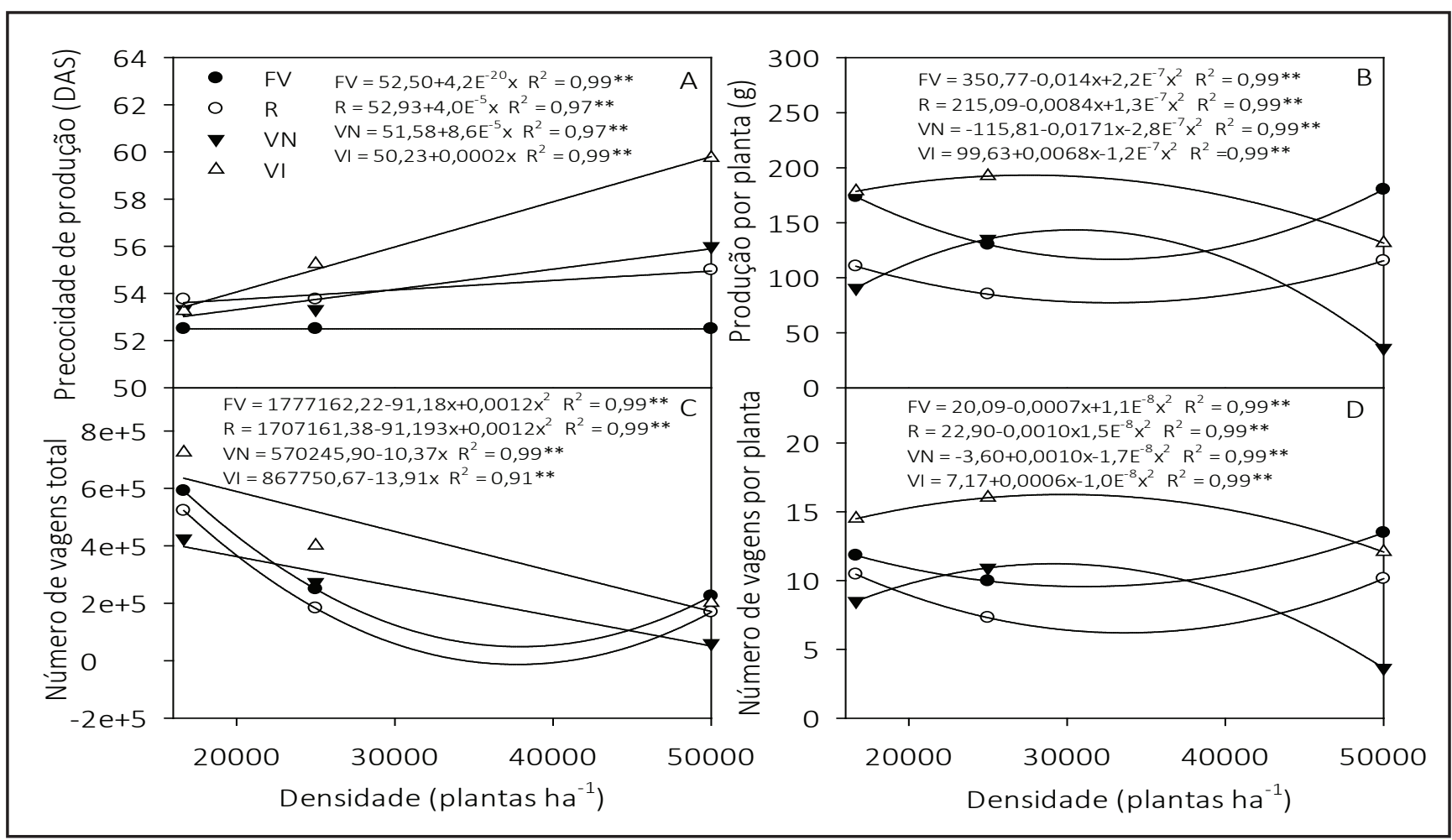

Figura 1. A) Precocidade de produção (DAS), B) produção por planta (g), D) número de vagens por planta e C) Número total de vagens de feijão de metro, em função de densidades de semeadura $\{\mathrm{A}$ ) precocity of production (DAS), B) production per plant (g), D) number of pods per plant and C) total number of pods, depending on planting density $\}$. Fortaleza, UFC, 2015. 
vertical (FV) e "V" normal (VN). As menores populações para os sistemas $\mathrm{FV}$ e $\mathrm{VN}$, possivelmente promoveram uma maior incidência de luz nas folhas em relação aos demais tratamentos, o que permitiu às plantas iniciarem sua fase produtiva de forma mais precoce, já que receberam maior quantidade de energia do que aquelas conduzidas da mesma forma, em menor espaçamento (Taiz \& Zeiger, 2013). Isso aconteceu possivelmente devido a uma menor competição entre as plantas nas menores densidades, por água, nutrientes e principalmente luz, o que levou estas a alcançar o ciclo produtivo de forma mais precoce.

Quanto à produção e número de vagens por planta, observou-se um ajuste quadrático em função das densidades (Figura 1B e 1D), onde o máximo para o sistema FV foi de $200,77 \mathrm{~g}$ na densidade de 50.000 plantas/ha e para VI de 195,96 g na densidade de 28.333 plantas/ha. Para o número de vagens por planta, a densidade de 50.000 plantas/ha foi a que proporcionou a maior quantidade de vagens para o sistema $F V$, com 12,59 vagens por planta, enquanto que para VI a densidade de 30.000 plantas/ha foi a que produziu maior número, com 16,2 vagens. Isto se deve principalmente à maior possibilidade de interceptação de luz pelas folhas nas densidades ótimas, o que contribui para uma maior taxa fotossintética e, consequentemente, maior produção de fotoassimiliados, quando comparado aos outros sistemas avaliados (Larcher, 2004). Para o número total de vagens, houve um ajuste linear decrescente para VN e VI, com redução do número de vagens em função do maior número de plantas (Figura 1C). De forma geral, os sistemas de tutoramento FV e VI possibilitaram produção de 67 e $16 \%$ e número de vagens por planta de no mínimo 21 e $17 \%$, respectivamente, superiores ao $\mathrm{R}$ na densidade de 50.000 plantas/ha. Em plantas de maxixe do reino também tutoradas, pesquisadores verificaram que o sistema com fitilho também foi o que possibilitou os melhores resultados de produção às plantas (Costa et al., 2005).

Para o comprimento médio de vagem, os maiores espaçamentos, menores densidades de plantas foram as que possibilitaram maiores comprimentos nos sistemas de tutoramento FV e VI, bem como para o R (Figura 2A). Para o VN, houve um comportamento quadrático, com máximos de 52,13 $\mathrm{cm}$ por vagem na densidade de 31.915 plantas/ha. De forma geral, todos os sistemas de tutoramento utilizados proporcionaram resultados superiores para esta característica se comparado ao R.

Para cultivares de feijão-caupi, cultivadas em diferentes densidades de cultivo, Cardoso et al. (1997) não observaram diferença entre o comprimento das vagens produzidas nos diferentes tratamentos.

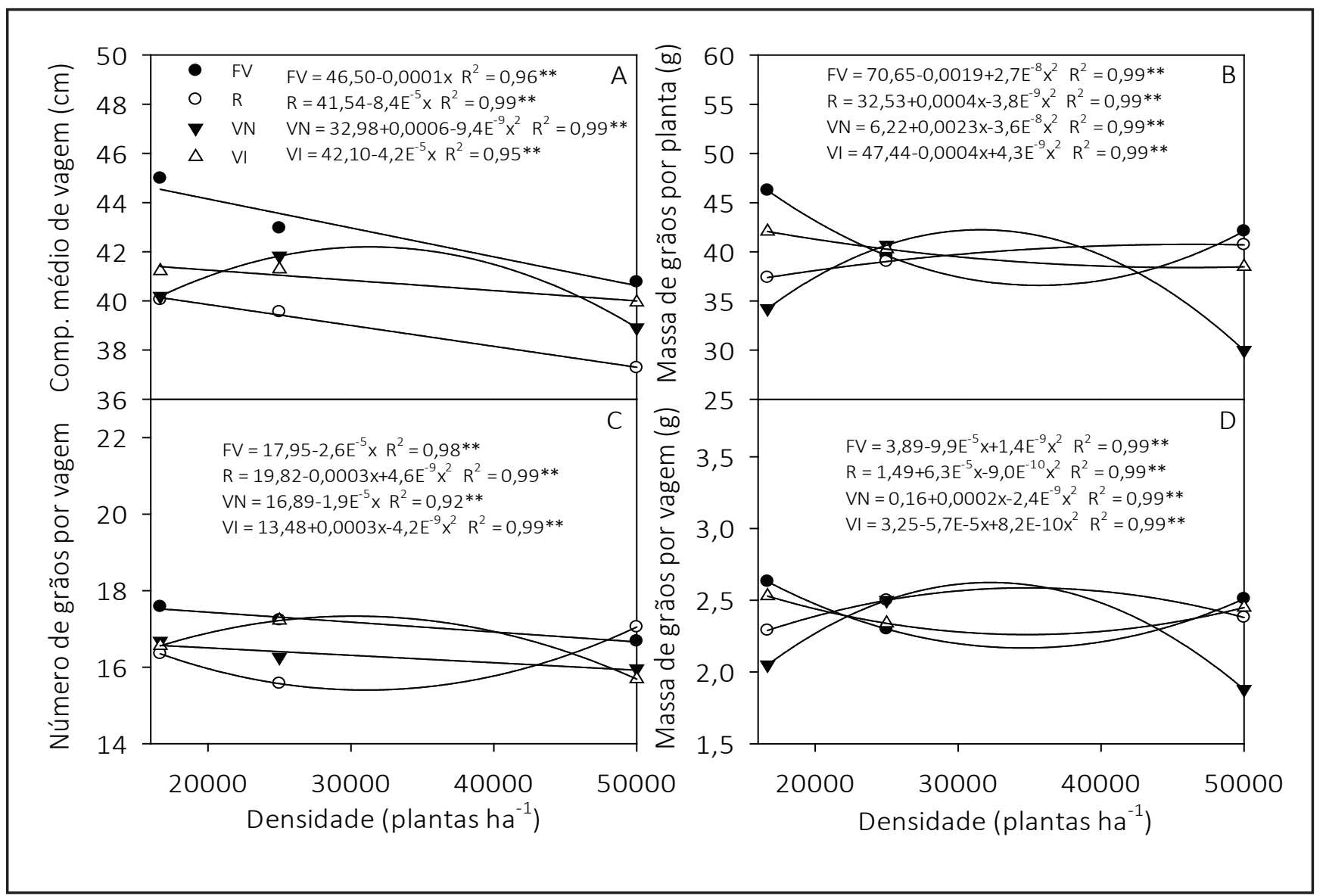

Figura 2. A) Comprimento médio de vagem $(\mathrm{cm}), \mathrm{B})$ massa de grãos por planta, D) massa de grãos por vagem (g) e C) número de grãos por vagem, de plantas de feijão de metro em função da densidades de semeadura $\{$ A) average length of pod (cm), B) mass of grains per plant and D) mass of grains per pod (g) and C) number of grains per pod, of asparagus bean plants according to seeding densities . Fortaleza, UFC, 2015. 
Para a massa de grãos por planta a densidade de 16.667 plantas por hectare (Figura 2B), foi a que proporcionou o maior acúmulo de massa de grãos para os sistemas FV e VI, com 46,48 e 41,96 g, respectivamente. De forma geral, os sistemas de tutoramento FV e VI possibilitaram a obtenção de maior massa de grãos por planta, no mínimo 35 e $23 \%$ a mais do que $\mathrm{R}$.

Cardoso et al. (1997), trabalhando com diferentes cultivares de feijãocaupi e densidades de plantas, também observaram redução na produção do número de vagens e da massa de grãos por planta em maiores densidades de plantas, isto é, menores espaçamentos. Segundo estes pesquisadores, a competição intraespecífica foi o motivo principal da redução. Seus resultados corroboram com o presente trabalho, já que a partir da densidade ótima, observou-se redução na massa de grãos nas maiores densidades (menores espaçamentos).

Quanto à massa de grãos por vagem, a densidade de 16.667 plantas foi a que proporcionou os melhores resultados, com 2,62 g para o FV e 2,52 g para o VI (Figura 2D). Ao trabalharem com diferentes sistemas de tutoramento em maxixe do reino, Costa et al. (2005) observaram que plantas tutoradas com fitilho produziram maior quantidade de frutos grandes em relação aos sistemas de tutoramento triangular e cerca vertical. Apesar de serem espécies totalmente diferentes, os resultados obtidos neste trabalho são coincidentes aos obtidos por aqueles pesquisadores, já que neste, o sistema com fitilho também se mostrou como um dos mais produtivos.

Para a característica número de grãos por vagem, os espaçamentos (densidade) influenciaram nessa característica, com redução á medida que se aumentou a população de plantas (Figura 2C) para FV e VI. Os sistemas de tutoramento FV e VI foram capazes de possibilitar às plantas a produção de vagens com maior número de grãos do que o $\mathrm{R}$, sendo de $4,61 \%$ e $0,85 \%$, respectivamente superiores.

Quanto à produtividade de grãos, o sistema de tutoramento por FV foi o que possibilitou a maior produtividade no espaçamento de $20 \mathrm{~cm}$ entre plantas, densidade de 50.000 plantas por hectare (Figura 3A). Para a característica produtividade total, o espaçamento que proporcionou os maiores valores foi o de $20 \mathrm{~cm}$ entre plantas para os sistemas de tutoramento FV, VI e para o R (Figura 3B). Para o VN, a máxima produtividade foi alcançada na densidade de 34.884 plantas, com 4,64 t/ha. No geral, para a produção de frutos, o tratamento FV combinado com espaçamento de $20 \mathrm{~cm}$ foi o que possibilitou a maior produtividade $(9,10 \mathrm{t} / \mathrm{ha}), 35 \%$ a mais do que o segundo melhor tratamento que foi VI combinado com espaçamento de $20 \mathrm{~cm}$, com 6,72 t/ ha.

Quando se tutora uma planta, o objetivo é evitar o contato de órgãos desta com o solo, o que favorece a qualidade dos frutos no momento da colheita (Marim et al., 2005; Guimarães et al., 2007, 2008). Além disso, reduz-se a infestação por doenças e pragas, bem como seus controles são favorecidos, já que não propicia um possível microclima favorável (Wamser et al., 2008). Por último, mas não menos importante, o tutoramento ajuda a amenizar os problemas referentes à sobreposição de folhas das plantas e, por consequência, possibilitam uma maior interceptação de energia solar já que mais folhas estarão expostas a luz, o que tende a favorecer a realização da fotossíntese bruta, o que possibilitaria uma maior produção de fotoassimilados implicando positivamente na produção (Taiz \& Zeiger, 2013), sendo possivelmente esta última vantagem a possível justificativa para os bons resultados obtidos para os sistemas tutorados em relação às plantas conduzidas de forma rasteira, mesmo que não haja alteração na fotossíntese líquida (instantânea) entre os sistemas de tutoramento.

No cultivo rasteiro, as plantas ficaram muito próximas devido ao restrito espaçamento disponibilizado para o desenvolvimento destas. Mesmo para o espaçamento máximo utilizado de $60 \mathrm{~cm}$ (16.667 plantas), na época da colheita, as plantas apresentavam-se com boa parte das folhas sobrepostas, sem receber diretamente a radiação solar. Conforme o espaçamento diminuía, mais evidente ficava a sobreposição e, consequentemente, a competição por luz entre as plantas.

Para as variáveis de trocas gasosas,
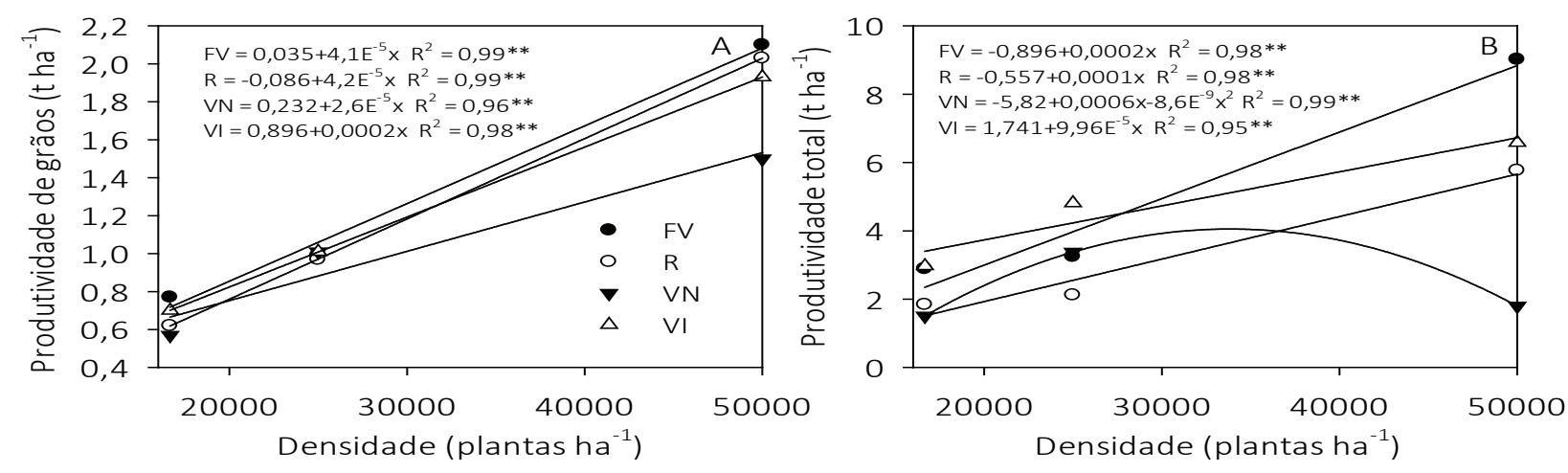

Figura 3. A) Produtividade de grãos (t/ha) e B) produtividade total (grãos + vagens, $t /$ ha) de plantas de feijão de metro em função de densidades de semeadura $\{\mathrm{A})$ grain yield $(\mathrm{t} / \mathrm{ha}$ ) and $\mathrm{B}$ ) total productivity (grains + pods, $\mathrm{t} / \mathrm{ha}$ ), of asparagus bean plants as a function of sowing densities $\}$. Fortaleza, UFC, 2015. 


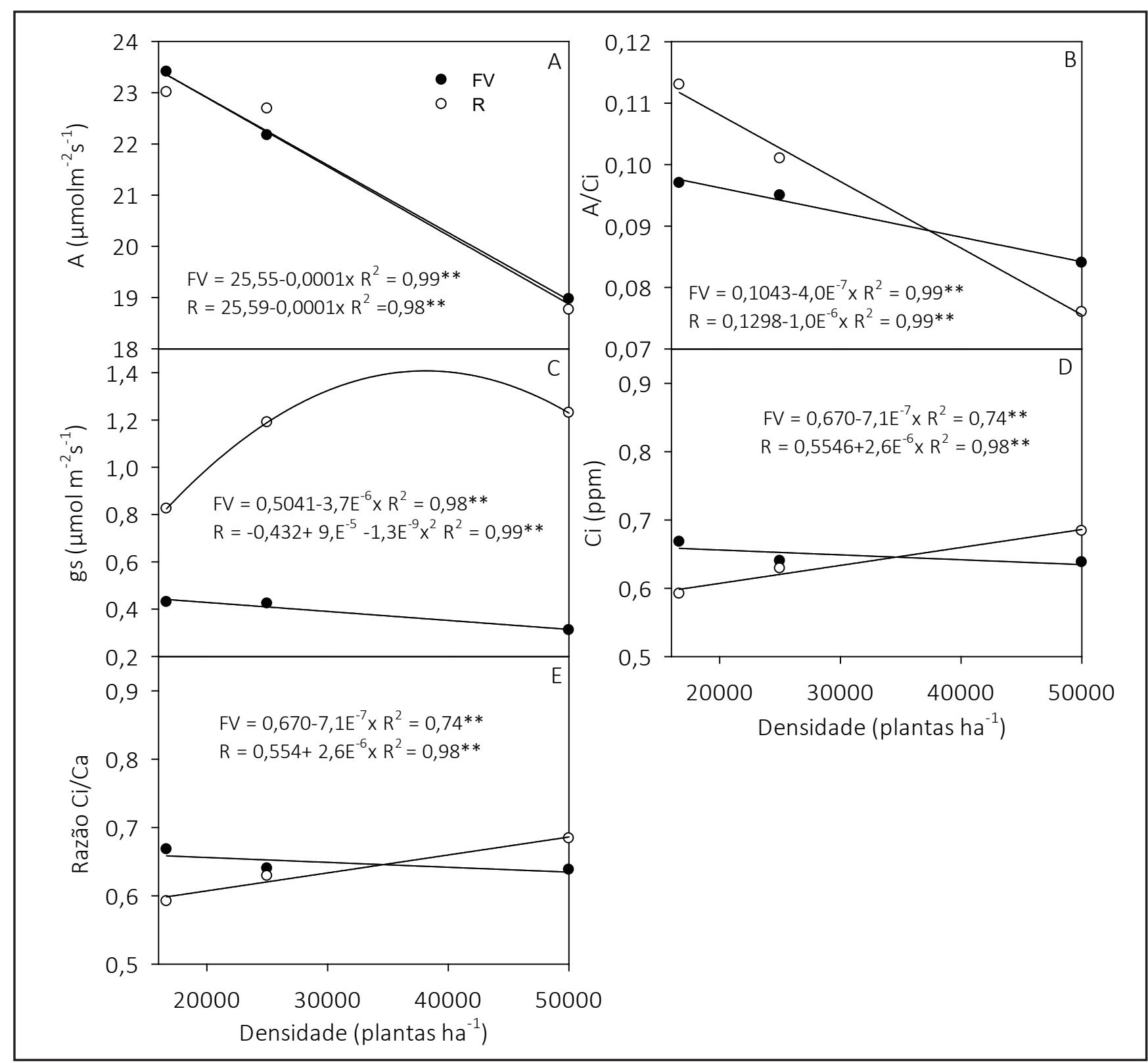

Figura 4. A) Fotossíntese líquida, B) eficiência instantânea de carboxilação (A/Ci), C) condutância estomática (gs), D) concentração interna de $\mathrm{CO}_{2}(\mathrm{Ci})$ e E) Razão Ci/Ca, de plantas de feijão de metro, cultivadas em três espaçamentos (20; 40 e 60 cm) combinados com quatro sistemas de tutoramento (FV= fitilho vertical, $\mathrm{VN}=$ "V" normal, $\mathrm{VI}=$ "V" invertido e R= sistema rasteiro) $\{\mathrm{A})$ net photosynthesis, B) instantaneous carboxylation efficiency (A/Ci), C) stomatal conductance (gs), D) internal $\mathrm{CO}_{2}$ concentration $(\mathrm{Ci})$ and $\mathrm{E}$ ) $\mathrm{Ci} / \mathrm{Ca}$ ratio, of asparagus bean cultivated in three spacing $(20 ; 40$ and $60 \mathrm{~cm})$ combined with four staking systems $(\mathrm{FV}=$ vertical staking with polypropylene cord, $\mathrm{VN}=$ two bamboo stakes as an V frame, $\mathrm{VI}=$ two bamboo stakes as an inverted $\mathrm{V}$ frame and $\mathrm{R}=$ creeping system) $\}$. Fortaleza, UFC, 2015.

observou-se interação $(p \leq 0,01)$ entre os sistemas de tutoramento e espaçamento somente para condutância estomática (gs). Para fotossíntese líquida $(A)$ e eficiência instantânea de carboxilação $(A / C i)$ houve efeito significativo apenas para o fator espaçamento. Enquanto para concentração interna de $\mathrm{CO}_{2}(\mathrm{Ci})$ e razão $\mathrm{Ci} / \mathrm{Ca}$ não houve diferença entre os tratamentos. Para melhor visualização desses resultados e levando-se em consideração a inexistência de diferença para estas características para os sistemas tutorados, mas destes últimos para o cultivo rasteiro, curvas de regressão foram ajustadas buscando-se comparar o sistema FV com o R. Escolheu-se o FV para comparar com o rasteiro, pelo fato deste ter proporcionado uma maior produtividade total e renda líquida quando comparado aos demais sistemas.

Para a fotossíntese líquida observouse um ajuste linear decrescente tanto para o cultivo rasteiro, como para o fitilho vertical em função do aumento das densidades (Figura 4A). Os resultados similares entre o cultivo rasteiro e o sistema FV, estão diretamente relacionados ao fato de que, à medida que se reduz a densidade de plantas, há uma provável elevação na fotossíntese devido ao maior número de folhas expostas a luz, porém, a partir de uma determinada densidade populacional, há competição por luz, principalmente devido à sobreposição das folhas 
das plantas que tendem a reduzir a fotossíntese líquida. Quando isso acontece, os estômatos tendem a ficar mais fechados assimilando menores volumes de $\mathrm{CO}_{2}$ (Larcher, 2004; Taiz \& Zeiger, 2013).

Neste ponto faz-se importante salientar que, apesar da fotossíntese líquida ter sido similar para o sistema FV em comparação ao $\mathrm{R}$, isso não significa dizer que as plantas cultivadas nos dois sistemas produziram quantidades globais similares de fotoassimilados. A fotossíntese líquida é uma medida instantânea que deve ser realizada em folhas totalmente expandidas expostas ao sol, ou seja, essa medida não representa a fotossíntese total de uma planta, mas apenas de um órgão (folha) dentre dezenas ou centenas de outros órgãos similares que existem na mesma planta. Assim, ainda que a fotossíntese líquida do sistema $\mathrm{FV}$ tenha sido igual ao $\mathrm{R}$, o maior número de folhas expostas a luz no caso do $\mathrm{FV}$, provavelmente possibilitou uma maior fotossíntese total na planta o que resultou na maior produção de biomassa.

Quanto à eficiência de carboxilação (A/Ci), observou-se comportamento similar ao da fotossíntese. Quanto menor foi a densidade de plantas, maior foi a fotossíntese, mais rapidamente o $\mathrm{CO}_{2}$ tendeu a ser consumido e maior tendeu ser a $A / \mathrm{Ci}$ (Figura 4B). Tal resultado implica dizer que, na prática, os sistemas tutorados possibilitaram às plantas uma maior eficiência na assimilação e transformação do $\mathrm{CO}_{2}$ atmosférico em fotoassimilados, sendo que estes contribuíram para o maior acúmulo de biomassa e, consequentemente, da produção.

Para a condutância estomática, as plantas conduzidas de forma rasteira apresentaram valores superiores às tutoradas independentemente das densidades (Figura 4C). Nas plantas tutoradas, a maior exposição das folhas à radiação solar deixam estas com temperaturas superiores àquelas das plantas rasteiras.

Essa temperatura mais elevada tende a causar uma maior perda de água por transpiração. Para evitar tais perdas, a planta reduz sua abertura estomática, o que acaba por resultar em uma redução na condutância dessas plantas. No caso das plantas rasteiras onde é recorrente o auto-sombreamento das folhas, a temperatura destas é menor, consequentemente, a transpiração é menor e as plantas tendem a deixar seus estômatos mais abertos, o que acaba levando a planta a apresentar maiores valores de condutância.

Deve-se salientar que, diferentemente da fotossíntese líquida que possibilita a obtenção de um resultado instantâneo específica de uma determinada folha, a condutância estomática de uma planta tende a apresentar menores variações na planta como um todo já que, de forma geral, a abertura e fechamento dos estômatos tende a ocorrer de forma mais coordenada na planta frente a uma determinada condição edafoclimática.

Para a condução rasteira foi verificado um comportamento quadrático, à medida que houve acréscimo na densidade de plantas. Em maiores adensamentos, geralmente há menor influência dos ventos nas áreas internas do cultivo. De forma geral, o vento pode atuar removendo a chamada camada de ar limítrofe (camada de ar que fica entre a superfície da folha e o ar atmosférico e que, geralmente, é mais espessa nos locais em que há estômatos). Quanto mais espessa a camada de ar limítrofe, maior tende a ser a resistência às trocas gasosas realizadas pelas plantas, ou seja, menor tende a ser a condutância

Tabela 1. Custo e quantidade de material e mão-de-obra utilizada para implantação de cada um dos sistemas de tutoramento (FV= fitilho vertical, VN= "V" normal, VI= "V" invertido e R= sistema rasteiro) combinados com três espaçamentos (20; 40 e 60 cm) para o cultivo de feijão de metro \{costs and amount of material and hand labor used to implement each of staking systems $(\mathrm{FV}=$ vertical staking with polypropylene cord, $\mathrm{VN}=$ two bamboo stakes as an $\mathrm{V}$ frame, $\mathrm{VI}=$ two bamboo stakes as an inverted $\mathrm{V}$ frame and $\mathrm{R}=$ creeping system) combined with three spacing $(20 ; 40$ e $60 \mathrm{~cm})$ for the cultivation of asparagus bean . Fortaleza, UFC, 2015.

\begin{tabular}{|c|c|c|c|c|c|}
\hline Materiais & Preço/unid (R\$) & $\mathbf{F V}^{1}$ & $\mathbf{V N}$ & VI & $\mathbf{R}$ \\
\hline Estacas de madeira $(2,5 \mathrm{~m})$ & 5,00 & 1334 & 1334 & 667 & - \\
\hline Fitilho (rolo de $1 \mathrm{~kg}$ ) & 18,00 & 28 & 28 & 28 & - \\
\hline Arame galvanizado $\mathrm{n}^{\circ} 18(\mathrm{~kg})$ & 15,00 & 28 & 28 & 28 & - \\
\hline Mão-de-obra (diária) & 30,00 & 12 & 18 & 14 & - \\
\hline Custo total (R\$) & & $7.594,00$ & $8.134,00$ & $4.259,00$ & 0,00 \\
\hline Produtividade (kg grãos) ${ }^{\mathrm{a}}$ & - & 9.200 & 5.780 & 6.590 & 1.810 \\
\hline Preço pago na CEASA $(\mathrm{R} \$ / \mathrm{kg})^{\mathrm{b}}$ & - & 4,17 & 4,17 & 4,17 & 4,17 \\
\hline Lucro bruto $(\mathrm{R} \$)^{\mathrm{c}}$ & - & $38.364,00$ & $24.102,60$ & $27.480,30$ & $7.547,70$ \\
\hline Lucro líquido parcial $(\mathrm{R} \$)^{\mathrm{d}}$ & - & $30.770,00$ & $15.968,60$ & $23.221,30$ & $7.547,70$ \\
\hline
\end{tabular}

aPara este cálculo considerou-se apenas o espaçamento considerado mais produtivo ( $20 \mathrm{~cm}$ entre plantas) \{for this calculation we considered only the more efficient spacing (20 cm between plants) $\}.{ }^{b}$ Valor foi baseado no preço de comercialização médio do feijão vagem na Ceasa Fortaleza-CE para o mês de novembro de 2014 (the value was based on the commercialization price for asparagus beans from Ceasa Fortaleza-CE, November 2014). Disponível em: <http://www3.ceasa.gov.br/prohortweb/?page=reports.relatorio_preco_medio_ mensal\&retTO $=$ consulta_relatorio_preco_medio_mensal $>$. ${ }^{c}$ Lucro bruto $=$ produtividade $\mathrm{x} \mathrm{R} \$ / \mathrm{kg}$; ${ }^{\mathrm{d}}$ Somente estão sendo descontados os gastos realizados com tutoramento, outros gastos já normalmente realizados para a cultura não estão sendo considerados \{we only deduced the expenses for staking, other expenses usually performed were not considered $\}.{ }^{1}$ Vertical staking with polypropylene cord. ${ }^{2}$ Two bamboo stakes as a V frame. ${ }^{3}$ Two bamboo stakes as an inverted V frame. ${ }^{4}$ Creeping system $\}$. 
estomática.

Por outro lado em condições de maiores espaçamentos (menores densidades) as plantas ficam mais sujeitas à interferência dos ventos, que atuam reduzindo essa camada. Para as plantas tutoradas não foi observada diferença da condutância estomática entre os diferentes espaçamentos. De forma geral, quanto mais distante a planta está da superfície do solo, mais ela está sujeita aos ventos, condição climática que promove a remoção da camada de ar limítrofe aumentando a transpiração. As plantas regulam essa perda transpiratória fechando os estômatos e, assim, reduzem a condutância estomática.

Para a concentração interna de $\mathrm{CO}_{2}$ (Ci; Figura 4D) e relação $\mathrm{Ci} / \mathrm{Ca}$ (Figura 4E), o sistema FV apresentou resultado oposto ao observado para o rasteiro, sendo verificado redução linear à medida que se aumentou a densidade de plantas. Tal diferença está relacionada principalmente à forma de condução das plantas. Plantas tutoradas de forma vertical, por apresentarem folhas mais expostas a condições climáticas como vento e luz, tornam-se mais suscetíveis a fecharem seus estômatos. Quando isso ocorre, a menor abertura estomática limita a entrada de $\mathrm{CO}_{2}$. Contrariamente, plantas de feijão de metro conduzido de forma rasteira, por apresentarem grande quantidade de folhas, provavelmente formam um microclima interno menos suscetível ao vento e a luz, o que favorece a manutenção da abertura do poro estomático e, consequentemente, a entrada de $\mathrm{CO}_{2}$ na folha.

No entanto, conforme haja um aumento da densidade populacional, pode haver uma redução cada vez maior da renovação do ar na área ocupada pelas plantas, o que favorece a formação do chamado fator de desacoplamento, fazendo com que aquela área possa ter um microclima diferenciado. Neste caso, mesmo os estômatos ficando abertos, a baixa taxa de renovação do ar, devido à barreira imposta pelas plantas mais adensadas e a sua própria arquitetura, com grande número de folhas e hastes, reduz a chegada de mais $\mathrm{CO}_{2}$. Isso, associado ao fato da contínua realização de fotossíntese, faz com que a concentração do $\mathrm{CO}_{2}$ seja reduzida na câmara subestomática.

Quanto aos custos de implantação, pode-se observar que, apesar dos maiores gastos verificados para os sistemas de tutoramento utilizados, as maiores produtividades proporcionadas por cada um deles, em relação ao cultivo rasteiro, justificam a sua adoção (Tabela 1).

Esse resultado se reveste de grande importância social, já que além de proporcionar um maior retorno líquido ao produtor, o gasto gerado com a compra de materiais e a contratação de mão de obra, para a execução das atividades relacionadas ao tutoramento, pode ajudar no desenvolvimento da comunidade local, já que, além de gerar retorno líquido para o comércio através da venda de materiais, gera emprego temporário que pode absorver a mão de obra disponível em certo local por determinado tempo.

Os sistemas de tutoramento em comparação ao cultivo rasteiro, favorecem a obtenção de mais frutos e grãos de feijão de metro, sendo estes de maior tamanho e massa. Desses, o sistema de tutoramento fitilho vertical (FV) foi o que proporcionou a obtenção dos maiores valores independentemente do espaçamento utilizado.

Apesar do gasto que se tem para implantação do sistema de tutoramento para o cultivo de feijão de metro, a produtividade proporcionada a partir da implantação deste sistema possibilita incrementos de produtividade que geram retornos que, além de cobrir os gastos gerados com a instalação das estruturas, podem gerar lucro líquido de até $\mathrm{R} \$ 30.770$, caso do sistema de tutoramento $\mathrm{FV}$.

\section{AGRADECIMENTOS}

Ao Conselho Nacional de Desenvolvimento Científico Tecnológico (CNPq) pelas bolsas de estudo fomentadas aos autores deste trabalho.

\section{REFERÊNCIAS}

AQUINO, AB; AQUINO, BF; HERNANDEZ,
FFF; HOLANDA, FJM; FREIRE, JM; CRISÓSTOMO, LA; COSTA, RI; UCHÔA, SCP; FERNADES, VLB. 1993. Recomendações de adubação e calagem para o estado do Ceará. Fortaleza: UFC. 248p.

CARDOSO, MJ; MELO, FB; ANDRADE JÚNIOR, AS. 1997. Densidade de plantas de caupi em regime irrigado. Pesquisa Agropecuária Brasileira 32: 399-405.

COSTA, CA; RAMOS, SJ; ALVES, DS; MARTINS, ER; FERNANDES, LA; LEITE, GLD; NAPOLEÃO, RL. 2005. Produção do maxixe-do-reino em função do sistema de tutoramento e do espaçamento. Horticultura Brasileira 23: 28-31.

FEITOSA, FRC; GARITA, SA; ARAÚJO, RB; GUIMARÃES, MA. 2015. Feijão de metro: Hortaliça-leguminosa indicada para climas quentes. Revista Campo \& Negócios HF 04: 32-35.

FERREIRA, DF. 2011. SISVAR: A Computer statistical analysis system. Ciencia e Agrotecnologia 35: 1039-1042.

FREIRE FILHO, FR. 1981. Origem e evolução do caupi (Vigna unguiculata (L.) Walp.). São Paulo: ESALQ. 29p.

GUIMARÃES, MA; SILVA, DJH; FONTES, PCR; CALIMAN, FRB; LOOS, RA; STRINGHETA, PC. 2007. Produção e sabor de frutos de tomateiro submetidos a poda apical e de cachos florais. Horticultura Brasileira 25: 259-263.

GUIMARÃES, MA; SILVA, DJH; FONTES, PCR; MATTEDI, AP. 2008. Produtividade e sabor dos frutos de tomate do grupo salada em função de podas. Bioscience Journal 24: 32-38.

KONGJAIMUN, A; KAGA, A; TOMOOKA, N; SOMTA, P; VAUGHAN, DA; SRINIVES, P. 2012. The genetics of domestication of yardlong bean, Vigna unguiculata (L.) Walp. ssp. unguiculata cv.-gr. Sesquipedalis. Annals of Botany 109: 1185-1200.

LARCHER, W. 2004. Ecofisiologia vegetal. São Carlos, SP: Rima artes. 531p.

MARIM, BG; SILVA, DJH; GUIMARÃES, MA; BELFORT, G. 2005. Sistemas de tutoramento e condução do tomateiro visando produção de frutos para consumo in natura. Horticultura Brasileira 23: 951-955.

PILUEK, K. 1994. The Importance of Yardlong Bean. In: Proc. $2^{\text {nd }}$ Symp. Vegetable Legumes. Kasetsart University Research and development Institute and ARC-AVRDC, Bangkok, Thailand.

SARUTAYOPHA, T; NUALSRI, C; SANTIPRACHA, Q; SAEREEPRARAT, V. 2007. Characterization and genetic relatedners among 37 yardlong bean an cowpea accessions based on morphological characters and RAPD analysis. Songklanakarin Journal of Science and Technology 29: 591-600.

TAIZ, L; ZEIGER, E. 2013. Fisiologia Vegetal. 5. ed. Porto Alegre: Artmed. 954p.

WAMSER, AF; BECKER, WF; SANTOS, JP; MUELLER, S. 2008. Influência do sistema de condução do tomateiro sobre a incidência de doenças e insetos-praga. Horticultura Brasileira 26: 180-185. 